\title{
Identification and characterization of four splicing variants of ovine POU1F1 gene
}

\author{
Estela Bastos ${ }^{\mathrm{a}, *}$, Sílvia Ávila ${ }^{\mathrm{b}}$, Alfredo Cravador ${ }^{\mathrm{c}}$, Robert Renaville ${ }^{\mathrm{d}}$, \\ Henrique Guedes-Pinto ${ }^{\mathrm{a}}$, José Luis Castrillo ${ }^{\mathrm{b}}$ \\ ${ }^{a}$ Centro de Genética e Biotecnologia (CGB-UTAD), Universidade de Trás-os-Montes e Alto Douro, Apdo. 1013, 5001-801 Vila Real, Portugal \\ ${ }^{\mathrm{b}}$ Centro de Biología Molecular Severo Ochoa (CSIC-UAM), Universidad Autónoma de Madrid, Cantoblanco 28049-Madrid, Spain \\ ${ }^{\mathrm{c}}$ Faculdade de Engenharia dos Recursos Naturais (FERN-UALG), Universidade do Algarve, Campus de Gambelas, 8005-139 Faro, Portugal \\ ${ }^{\mathrm{d}}$ Unité de Biologie Animale et Microbienne, Faculté Universitaire des Sciences Agronomiques, Bat. 92, B-5030 Gembloux, Belgium
}

Received 9 February 2006; received in revised form 26 May 2006; accepted 31 May 2006

Available online 15 June 2006

Received by T. Sekiya

\begin{abstract}
Expression of POU1F1 gene, a member of the POU homeodomain family of transcription factors, is necessary for normal differentiation, development and survival of three anterior pituitary cell types (thyrotrophs, somatotrophs and lactotrophs) and for the proper expression of growth hormone $(G H)$, prolactin $(P R L)$, thyroid-stimulating hormone $(T S H)$ genes and POU1F1 gene itself. Alternative splicing forms of this gene have been reported in different species, with few functional studies. Apart from the POU1F1-Wild-type with the expected length, in this work we isolated three additional splicing variants: $P O U 1 F 1-\beta$, with a 78 bp insert in the trans-activation domain; $P O U 1 F 1-\gamma$ that lacks exon 3 and $P O U 1 F 1-\delta$ that lacks exons 3, 4 and 5. Four different protein isoforms were also detected by Western blot in the sheep pituitary tissue. Functional assays were performed to study the trans-activation of $G H$ and $P R L$ promoters by the splicing variants. Regarding the $P R L$ promoter, the $\beta$ variant presented only $12 \%$ of the Wild-type trans-activation capacity. Variants $\gamma$ and $\delta$ showed no capacity to trans-activate $P R L$ promoter. Both $\gamma$ and $\delta$ variants acted as repressors of Wt, reducing significantly the trans-activation made by Wt alone $(p<0.05)$. Concerning the $G H$ promoter, the $\beta$ variant presented a trans-activation capacity $10 \%$ higher than Wt. Wt and $\beta$ variants strongly interact in the activation of $G H$ promoter doubling the trans-activation potential of Wt. Variants $\gamma$ and $\delta$ showed no capacity to trans-activate the $G H$ promoter and both acted as repressors, reducing significantly $(p<0.001)$ the trans-activation performed by Wt. This work presents, for the first time, the characterization of four splicing forms of Ovis aries POU1F1 gene.
\end{abstract}

(C) 2006 Elsevier B.V. All rights reserved.

Keywords: Alternative splicing; PIT-1; Sheep; Transcription factor; Gene regulation

\section{Introduction}

POU1F1 (also named PIT-1 or GHF-1) is a member of the POU homeodomain family of transcription factors (Bodner et al.,

Abbreviations: PCR, polymerase chain reaction; RT-PCR, reverse transcription-PCR; bp, base pair(s); aa, amino acid; CFS, calf serum; dNTPs, deoxynucleotide triphosphates; nt, nucleotide(s); cDNA, DNA complementary to RNA; mRNA, messenger RNA; GH, growth hormone; PRL, prolactin; TSH, thyroid-stimulating hormone; kDa, kilodalton(s); AMV, avian myeloblastosis virus; TAD, trans-activation domain; DMEM, Dulbecco's modified Eagle medium; Wt, Wild-type.

* Corresponding author. Tel.: +351 259374624; fax: +351 259350572.

E-mail address: ebastos@utad.pt (E. Bastos).
1988; Ingraham et al., 1988). It is mainly expressed in the pituitary and its expression is necessary for the normal differentiation, development and survival of three adenohypophysis cell types, thyrotrophs, somatotrophs and lactotrophs (Li et al., 1990; Simmons et al., 1990). It is also important for the proper expression of growth hormone $(G H)$, prolactin (PRL) (Lefevre et al., 1987; Nelson et al., 1988), thyroid-stimulating hormone (TSH) (Li et al., 1990) and POU1F1 gene itself (Chen et al., 1990; McCormick et al., 1990).

The POU1F1 gene, as described by Theill et al. (1989, 1992), contains six exons and five introns and encodes a protein with $33 \mathrm{kDa}$. This transcription factor contains two important regions for the transcriptional regulation of target promoters: a 
$\mathrm{N}$-terminal trans-activation domain (TAD) spanning amino acids 1 to 80 and a C-terminal DNA-binding and dimerization domain that consists of a POU-specific domain $\left(\mathrm{POU}_{\mathrm{S}}\right.$ from aa 128 to 198) and a POU homeodomain ( $\mathrm{POU}_{\mathrm{HD}}$ from aa 214 to 273). While $\mathrm{POU}_{\mathrm{S}}$ and $\mathrm{POU}_{\mathrm{HD}}$ are essential for high-affinity DNA-binding, TAD is important for the trans-activation of the target genes.

Until now, POU1F1 encoding cDNAs were cloned in 18 species from three different Classes: Mammalia, Aves and Actinopterygii, as summarized by Bastos et al. (2006).

Alternative splicing is a very common process that allows the expansion of the proteome. It was mentioned for the first time by Berget et al. (1977) and it was proposed that $5 \%$ of the genes presented alternative splicing (Sharp, 1994). Later, Modrek and Lee (2002) anticipated that 40 to $60 \%$ of the genes undertake alternative splicing forms and the frequency of this event should be identical between mammals, flies and worms (Brett et al., 2002). This number increased to $74 \%$ in a study using microarrays (Johnson et al., 2003) and was corroborated by the analysis of the transcriptome of human chromosomes 21 and 22 which showed that alternative splicing occurs in more than $80 \%$ of the genes (Kampa et al., 2004).

The alternative splicing process was studied in the rat POU1F1 gene. Theill et al. (1992), Konzak and Moore (1992) and Morris et al. (1992) published independent results showing an alternative transcript in this gene, with different nomenclatures: GHF2, Pit$1 \beta$ and Pit-1a, respectively. This $P O U 1 F 1$ alternative form arises from the use of an alternative $3^{\prime}$ splice acceptor at the end of the first intron and contains an insertion of $78 \mathrm{bp}$ downstream the nucleotide 142 relatively to the initiation ATG codon, giving rise to a 26 aa insertion at position 48 of the TAD domain. Functional analysis of this POU1F1 alternative splicing showed that $\beta$ mRNA and protein are $10 \%$ less abundant than Wild-type $(\mathrm{Wt})$. The POU1F1- $\beta$ and other splicing variants have been described for other mammalian species, few of them being the object of functional studies as well. It is the case of Mus musculus (Haugen et al., 1994), Sus scrofa (Yu et al., 2001), Homo sapiens (Delhase et al., 1995) and Macaca mulatta (Schanke et al., 1997). The alternative splicing of POU1F1 gene was not detected in nine fish species analysed. Nevertheless, an insertion of 26 aa $(\beta)$, similar to the one detected in birds and mammals, was observed (Chiu et al., 2002), suggesting a possible important role of this $\beta$ domain.

In order to study the alternative splicing of POU1F1 gene, we proposed to analyse the mRNAs expressed in the ovine pituitary. The bigger size of the sheep hypophysis comparing with rat and mouse can allow us to achieve a copious amount of mRNAs and proteins. In this work, we report the identification and characterization of four splicing variants of Ovis aries POU1F1 gene: $\mathrm{Wt}$, $\beta, \gamma$ and $\delta$. As far as we know, it is the first time that alternative transcripts of POU1F1 are identified in sheep. In addition, functional assays were carried out in order to study the ability of all the variants on the trans-activation of $G H$ and $P R L$ promoters.

\section{Material and methods}

\subsection{RNA extraction}

Total pituitary RNA was isolated from the sheep hypophysis, using the guanidinium thiocyanate/phenol/chloroform method, described by Chomczynski and Sacchi (1987), and Trizol reagent (Invitrogen Corporation), according to the supplier's recommendations.

\subsection{RT-PCR of POU1F1}

RT-PCRs were optimized in order to identify ovine POU1F1 mRNAs. Primers for RT-PCR reactions were designed based on the genomic sequences reported by Bastos et al. (2006), with the GenBank accession nos. AJ549204, AJ549205, AJ549206, and AJ549207.

Forward primer $\left(\mathrm{P}_{1} \mathrm{~F}\right)$, located in exon 1, two bases upstream of the initiation codon, with the sequence 5'-GAA TGA GTT GCC AAC CTT TTA CTT CG-3' was combined with the reverse primer $\left(\mathrm{P}_{6} \mathrm{R}\right)$, located in exon 6 , immediately downstream of the stop codon, with the sequence $5^{\prime}$-AAA TCT TAT CTG CAT TCG AGA TGC TCC-3'. To confirm the results, a second reverse primer was tested $\left(\mathrm{P}_{6 \mathrm{a}} \mathrm{R}\right)$ with the sequence $5^{\prime}$ AAA GTA GAA GAG AAA CAC TTC TG-3', located 130 bp downstream. The RT-PCRs were performed in two step reactions (Access RT-PCR System, Promega). For the reverse transcriptase reaction, the mix contained $14.4 \mu 1 \mathrm{H}_{2} \mathrm{O}, 1.5 \mu 1 \mathrm{MgSO}_{4}$ $25 \mathrm{mM}, 5 \mu \mathrm{l}$ buffer $5 \times, 0.5 \mu \mathrm{l}$ dNTPs mix $10 \mathrm{mM}, 0.8 \mu \mathrm{l}$ of reverse primer $10 \mu \mathrm{M}, 0.5 \mu \mathrm{l}$ of AMV reverse transcriptase $(5 \mathrm{U} /$ $\mu \mathrm{l})$ and $1 \mu \mathrm{l}$ RNA $(1 \mu \mathrm{g} / \mathrm{il})$. The reaction was performed at $48^{\circ} \mathrm{C}$ for $45 \mathrm{~min}$ and $94{ }^{\circ} \mathrm{C}$ for $2 \mathrm{~min}$. At the end of this reaction, $0.5 \mu \mathrm{l}$ $T f l$ DNA polymerase $(5 \mathrm{U} / \mu \mathrm{l})$ and $0.8 \mu \mathrm{l}$ of reverse primer $(10 \mu \mathrm{M})$ were added and PCR amplification was carried out with the following temperatures: $94^{\circ} \mathrm{C}$ for $2 \mathrm{~min}$, and 35 cycles with: denaturation at $94^{\circ} \mathrm{C}$ for $1 \mathrm{~min}$, primer hybridization at $60^{\circ} \mathrm{C}$ for $1 \mathrm{~min}$; extension at $68^{\circ} \mathrm{C}$ for $2 \mathrm{~min}$; followed by a final extension of $7 \mathrm{~min}$ at $68^{\circ} \mathrm{C}$.

Another RT-PCR reaction was performed in order to amplify a cDNA fragment from exon 1 to exon 3 . Forward primer $\left(\mathrm{P}_{1 \mathrm{a}} \mathrm{F}\right)$, with the sequence 5'-TGT GGG AAT GAG TTG CCA ACC-3' was combined with reverse primer $\left(\mathrm{P}_{3} \mathrm{R}\right)$, with the sequence $5^{\prime}$ GGA GAA TCC ATG TCT ATT GGC T-3'. In this case, RT and PCR reactions were performed simultaneously, with one-step mix (OneStep RT-PCR kit, Qiagen), using $5 \mu$ RT-PCR buffer, $1 \mu \mathrm{ldNTPs} 10 \mathrm{mM}, 1.5 \mu \mathrm{l}$ of each primer $(10 \mu \mathrm{M}), 1 \mu \mathrm{l}$ enzyme, $14.5 \mu \mathrm{l} \mathrm{H}_{2} \mathrm{O}$ and $0.5 \mu \mathrm{l}$ RNA $(1 \mu \mathrm{g} / \mu \mathrm{l})$. The amplification cycle was as follows: $50{ }^{\circ} \mathrm{C}$ for $30 \mathrm{~min}, 95^{\circ} \mathrm{C}$ for $15 \mathrm{~min}$, followed by 30 cycles at $94^{\circ} \mathrm{C}$ for $1 \mathrm{~min}, 60^{\circ} \mathrm{C}$ for $1 \mathrm{~min}$ and $72^{\circ} \mathrm{C}$ for $1 \mathrm{~min}$ and a final extension at $72{ }^{\circ} \mathrm{C}$ for $10 \mathrm{~min}$.

The RT-PCR products were separated by electrophoresis on agarose gels and stained with ethidium bromide. The DNA fragments obtained were purified and subcloned into pBluescript II KS plasmid by T/A cloning. All the constructs were fully sequenced, in both directions, by the dideoxynucleotide chain termination method.

\subsection{Expression vectors and reporter gene constructs}

The four $O$. aries RSV-POU1F1 plasmids were constructed by replacing the HindIII-NotI rat GHF-1 coding fragment of $\mathrm{RSV}_{\text {rat }} G H F-1$ (Theill et al., 1989) by a similar fragment containing the coding sequence of ovine POU1F1-Wt, $-\beta,-\gamma$ and $-\delta$ 
transcripts obtained by HindIII-NotI digestion of previously sequenced $\mathrm{pKS}$ cDNA vectors.

All the constructs were analysed by restriction enzyme digestion to confirm the direction (EcoRI) and the length (NotI and HindIII) of the inserts.

\subsection{Cell culture and transient transfection assays}

HeLa and RAT-6 cells were grown in Dulbecco's modified Eagle medium (DMEM) (Invitrogen Corporation) supplemented with $10 \%$ calf serum (CFS). In the case of HeLa cells, transient transfections were performed using cationic lipids (Lipofectamine 2000, Invitrogen Corporation) with cells at $90 \%$ confluence. DNA was mixed with DMEM, while lipofectamine reagent was mixed with DMEM, separately. After 5 min incubation, they were mixed together and incubated at RT for $20 \mathrm{~min}$. During this time, cells were prepared. The medium was eliminated and a new medium, with no antibiotics or serum, was added. The complex lipofectamine-DNA was well mixed within each well and after $5 \mathrm{~h}$ of incubation, the medium with serum in double dose was added to each well. Cells were incubated during $48 \mathrm{~h}$ and subsequently transfected cells were harvested and assayed for luciferase activity and protein content. In the case of RAT- 6 cells, transient transfections were performed by electroporation. Tripsinized RAT-6 cells were mixed with supercoiled plasmid DNA in $10 \%$ CFS DMEM containing Hepes $10 \mathrm{mM}$ and $\mathrm{NaCl} 30 \mathrm{mM}$, transferred to an electroporation cuvette, and subjected to an electrical pulse ( $220 \mathrm{~V}, 1050 \mu \mathrm{F}$, time constant $35-40 \mathrm{~ms})$, and then diluted into pre-warmed medium with $10 \%$ serum. pRLCMV plasmid (Promega) was also used as a transfection-efficiency internal control. Cell survival was typically $30-40 \%$ of that from non-electroporated controls. In both transfection methods, the plasmids were purified by the QIAGEN plasmid purification procedure and an identical level of plasmid DNA was cotransfected in each assay, using pKS as carrier DNA. At the appropriated time, cells were washed twice with phosphate buffer saline and Firely and Renilla luciferase activities were measured using the Dual Luciferase Assay (Promega), using a Sirius Luminometer (Berthold Detection Systems). Results were normalized against Renilla luciferase activity and presented as relative activity with respect to control (considered as 100\%) and to total protein in the extract supernatants. Results were expressed as the mean fold activation of the promoters \pm S.E.M. in triplicate. The significance of the differences between the conditions was calculated by two-tailed Student's $t$-tests. Protein assays were performed according to the Bradford's method, using commercially available reagents (Bio-Rad).

\subsection{Protein electrophoresis and Western blot analysis}

Proteins were extracted from the same sheep pituitary, using the protocol described in Trizol reagent (Invitrogen Corporation),

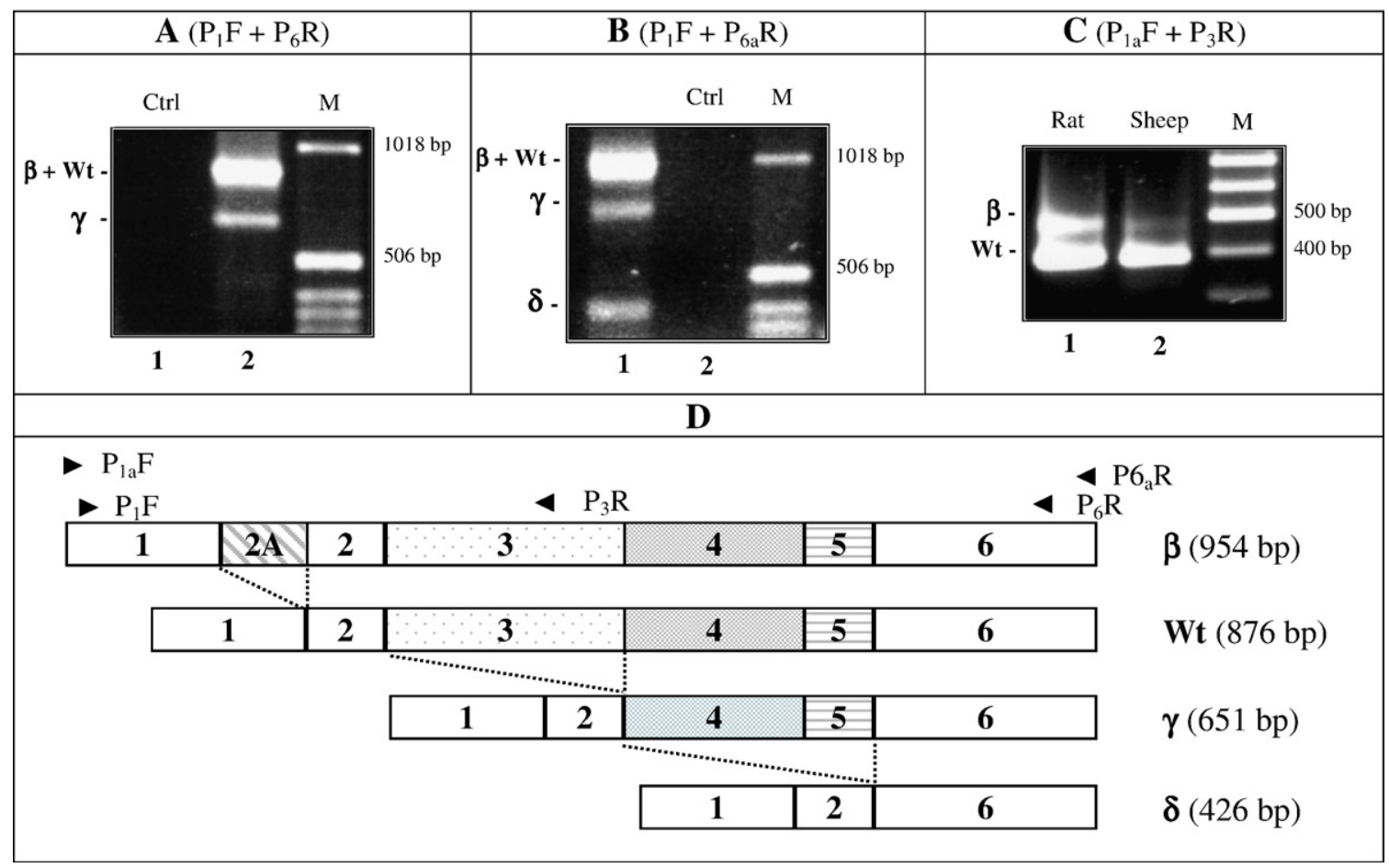

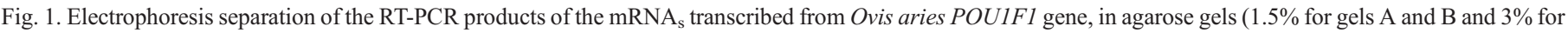

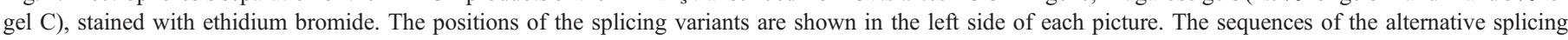

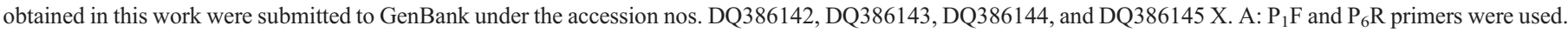

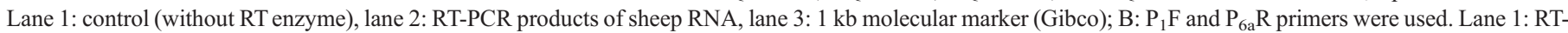

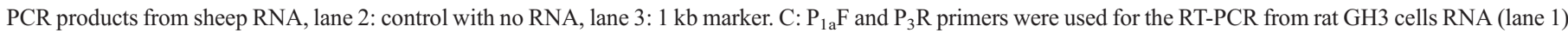

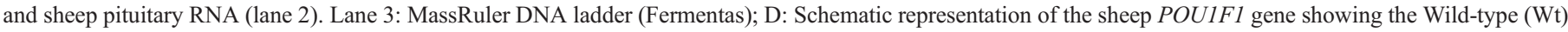

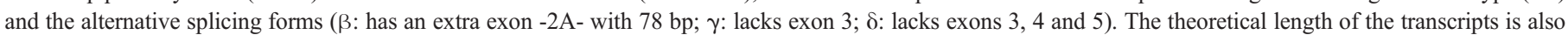

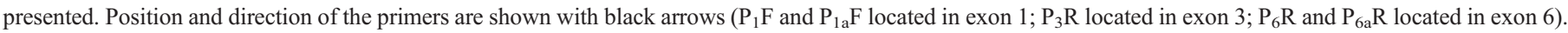


simultaneously with RNA extraction as a separate step. $10 \mu \mathrm{l}$ of protein extract were mixed with $20 \mu \mathrm{l}$ of $3 \times$ sample buffer (450 mM Tris-HCl pH 6.8; 30\% glycerol; 6\% SDS; 4.6\% DTT and $0.06 \%$ bromophenol blue), sonicated and boiled during $3 \mathrm{~min}$. Proteins were then fractionated by SDS-PAGE at $12 \%$ concentration and electrotransferred to an activated PVDF membrane (Bio-Rad). Pre-stained SDS-PAGE standard was used to estimate the MW $(\mathrm{kDa})$ of the detected bands (SeeBlue Plus2, Invitrogen Corporation). After transfer, the protein containing membrane was blocked using ECL Advance Blocking Agent (ECL Advance Western Blotting Detection kit, Amersham Biosciences) and reacted during $1 \mathrm{~h}$ with an anti-rat POU1F1 primary antibody diluted 1:500. This antibody was used in the studies of bovine (Bodner et al., 1988), human (Vila et al., 1993) and pig (Malagon et al., 1996) POU1F1. This first incubation was followed by a $1 \mathrm{~h}$ incubation with donkey anti-rabbit coupled to horseradish peroxidase secondary antibody (Amersham Biosciences) diluted 1:50,000. Antibody binding was visualized by chemiluminescence system (ECL Advance Western Blotting Detection kit, Amersham Biosciences).

\section{Results}

\subsection{Four different transcripts of POU1F1 gene were detected in the $O$. aries pituitary}

In order to appraise the existence of new splicing variants of POU1F1 gene and to understand their function, RT-PCR reactions were performed using RNA purified from ovine pituitary. Fig. 1-A shows the results of the RT-PCR reaction using primers $\mathrm{P}_{1} \mathrm{~F}$, located two bases upstream of the initiation codon, in exon 1 , and $\mathrm{P}_{6} \mathrm{R}$, located $5 \mathrm{nt}$ downstream of the stop codon, in exon 6. A stronger band, corresponding to approximately $900 \mathrm{bp}$, was detected. Additionally, a shorter fragment with approximately

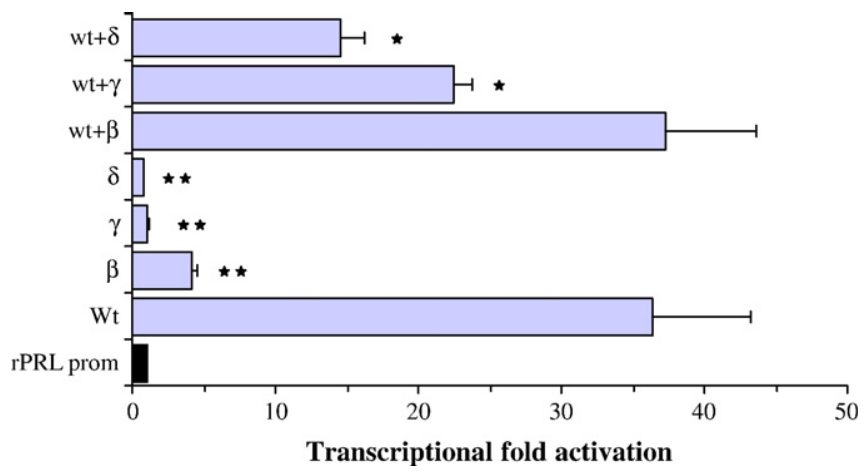

Fig. 2. Trans-activation of rat $P R L$ promoter (inserted on luciferase reporter plasmid) using different combinations of Ovis aries POU1F1 transcripts (inserted on expression vectors) in HeLa cells. $0.15 \mu \mathrm{g}$ of reporter plasmid and $0.45 \mu \mathrm{g}$ of each expression vector were used in the experiments. A total DNA amount of $1.5 \mu \mathrm{g}$ was maintained using pKS carrier DNA. The cells were analysed for luciferase activity $48 \mathrm{~h}$ after transfection and the results of the average of three repetitions are presented as fold activation (relatively to the basal expression of each reporter plasmid). Starred bars are significantly different from Wild-type $(* * p<0.01$ and $* p<0.05)$. From bottom to top: lane 1 - promoter alone; lanes 2 to 8 : promoter with different combinations of expression plasmids. Lane $2-\mathrm{Wt}$; lane $3-\beta$; lane $4-\gamma$; lane $5-\delta$; lane $6-(\mathrm{Wt}+\beta)$; lane $7-(\mathrm{Wt}+\gamma)$; lane $8-(\mathrm{Wt}+\delta)$.
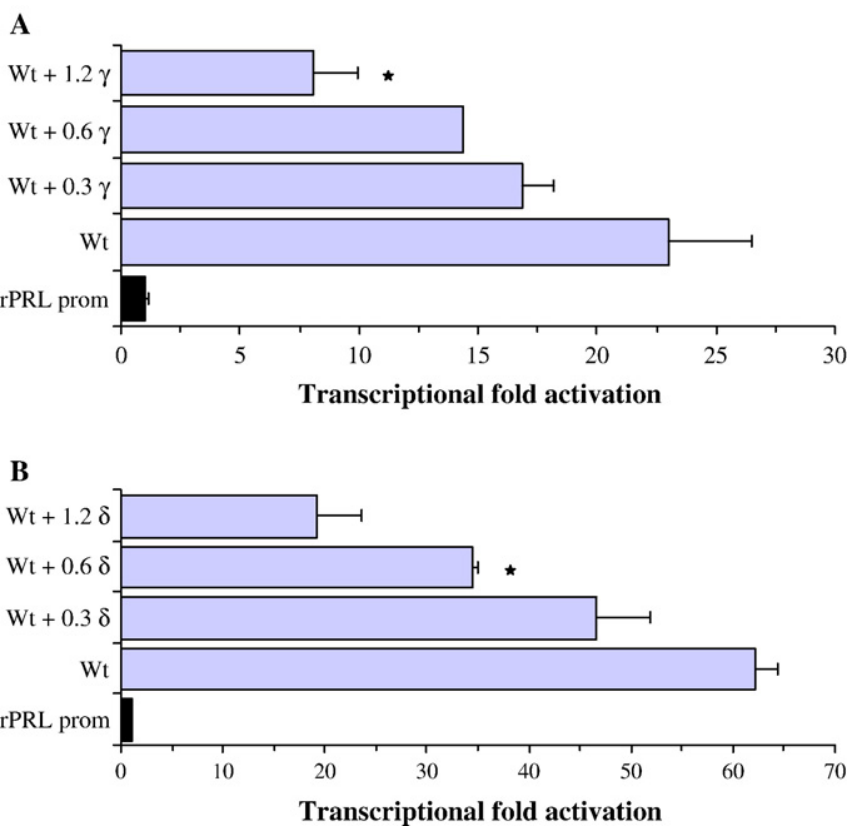

Fig. 3. Trans-activation of rat $P R L$ promoter (inserted on luciferase reporter plasmid) by the Ovis aries expression vector pRSV-POU1F1-Wt and with increasing amounts of pRSV-POU1F1- $\gamma$ (A) and pRSV-POU1F1- $\delta$ (B), in HeLa cells. A total DNA amount was maintained using pKS carrier DNA in each experiment. The cells were analysed for luciferase activity $48 \mathrm{~h}$ after transfection and the results of the average of three repetitions are presented as fold activation (relatively to the basal expression of each reporter plasmid). Starred bars are significantly different from Wild-type $\left({ }^{*} p<0.05\right)$. A - From bottom to top: lane $1-0.15 \mu \mathrm{g} P R L$ promoter; lane $2-0.15 \mu \mathrm{g} P R L$ promoter and $0.3 \mu \mathrm{g}$ pRSV-POU1F1-Wt; lane 3 - similar to lane 2 plus $0.3 \mu \mathrm{g}$ pRSV-POU1F1- $\gamma$; lane 4 - similar to lane 2 plus $0.6 \mu \mathrm{g}$ pRSV-POU1F1- $\gamma$; lane 5 - similar to lane 2 plus $1.2 \mu \mathrm{g}$ pRSV-POU1F1- $\gamma$. B - Similar to A, with increasing the amounts of pRSV-POU1F1- $\delta$.

$600 \mathrm{bp}$ was detected and a weaker band with lower molecular weight was faintly visible. The RT-PCR control on lane 1 (without RT enzyme) confirmed the absence of genomic DNA contamination.

To corroborate this result, we used a new reverse primer $\left(\mathrm{P}_{6 \mathrm{a}} \mathrm{R}\right)$ downstream of $\mathrm{P}_{6} \mathrm{R}$ to prime the RT-PCR (Fig. 1-B). Three intense bands were amplified, confirming that they correspond to the same fragments observed with the previous primers (lane 1). The control reaction, without RNA (lane 2), confirmed the absence of contaminations. A third RT-PCR reaction was performed, using a forward primer $\left(\mathrm{P}_{1 \mathrm{a}} \mathrm{F}\right)$ located $5 \mathrm{bp}$ upstream of $\mathrm{P}_{1} \mathrm{~F}$, in exon 1 and a reverse primer located in exon $3\left(\mathrm{P}_{3} \mathrm{R}\right)$. Fig. $1-\mathrm{C}$ shows the result of this RT-PCR using RNA extracted from ovine pituitary (lane 2) and from rat pituitary GH3 cell line (lane 1). Two fragments of $480 \mathrm{bp}$ and $400 \mathrm{bp}$ were observed, in both cases, suggesting that the strong upper band in Fig. 1A and Fig. $1 \mathrm{~B}$, is the result of two overlapping bands of similar length.

The cloning and sequencing of all the DNA bands detected in the agarose gels confirmed the existence of four alternative spliced transcripts of the POU1F1 gene. The sequences were submitted to GenBank with the accession nos. DQ386142, DQ386143, DQ386144, and DQ386145. The POU1F1-Wildtype $(\mathrm{Wt})$ open-reading frame (ORF) showed the expected length (873 bp) and the same cDNA sequence as compared with 


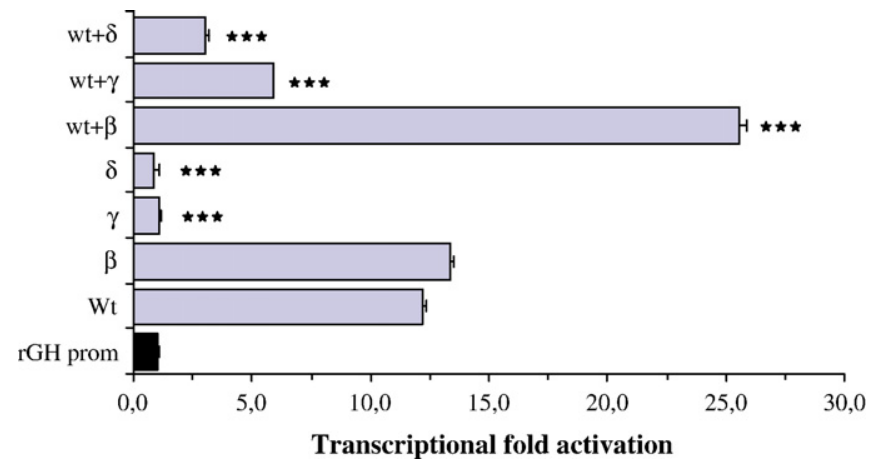

Fig. 4. Trans-activation of rat $G H$ promoter (inserted on luciferase reporter plasmids) using different combinations of Ovis aries POU1F1 transcripts (inserted on expression vectors) in RAT-6 cells. The cells were analysed for luciferase activity $48 \mathrm{~h}$ after transfection and the results of the average of three repetitions are presented as fold activation (relatively to the basal expression of each reporter plasmid). Starred bars are significantly different from Wild-type $(* * * p<0.001)$. From bottom to top: lane 1 — promoter alone; lanes 2 to 8: promoter with different combinations of expression plasmids. Lane $2-\mathrm{Wt}$; lane $3-\beta$; lane $4-\gamma$; lane $5-\delta$; lane $6-(\mathrm{Wt}+\beta)$; lane $7-(\mathrm{Wt}+\gamma)$; lane $8-(\mathrm{Wt}+\delta)$.

the previously reported by Bastos et al. (2006) and eight nucleotide differences when compared with another ovine cDNA sequence (Thomas et al., 2000), suggesting possible polymorphisms. An alternative splicing form, named POU1F1- $\beta$, showed a $78 \mathrm{bp}$ insert downstream of the nucleotide 142 relatively to the ATG initiation codon and a 954 bp ORF. A second alternative splicing form, we called POU1F1- $\gamma$, showed a $651 \mathrm{bp}$ ORF and it differs from Wt by lacking the entire 225 bp of exon 3 . Finally, a third alternative splicing, with a 426 bp ORF was showed, lacking the exons 3, 4 and 5, and named POU1F1- $\delta$.
A schematic representation with all POU1F1 mRNAs described in the present work is shown in Fig. 1-D: the Wildtype $(\mathrm{Wt})$ and the three alternative transcripts $(\beta, \gamma$ and $\delta)$. The respective length, the particular exon profile and the localization of the primers used for the RT-PCRs are also shown.

\subsection{Trans-activation of the prolactin promoter}

The cDNA transcripts with the four POU1F1 ORFs were subcloned into eukaryotic expression vectors under the control of RSV promoter (pRSV vectors), in order to perform transactivation assays of prolactin $(P R L)$ promoter. Transcription activation of $P R L$ promoter by the four $P O U 1 F 1$ expression vectors or by a combination of $\mathrm{Wt}$ and all the isoforms were analysed in non-pituitary HeLa cells (Fig. 2).

The POU1F1-Wt showed a strong trans-activation activity but POU1F1- $\beta$ showed only a weak transcriptional activity (36.4 vs 4.2 fold). POU1F1- $\gamma$ and POU1F1- $\delta$ isoforms did not trans-activate the $P R L$ promoter.

When Wt and $\beta$ POU1F1 expression vectors were cotransfected no significant effect on $P R L$ promoter activity was shown relatively to $\mathrm{Wt}$ alone. A significant inhibition of POU1F1-Wt induced trans-activation was observed when POU1F1- $\gamma$ or POU1F1- $\delta$ expression vectors were co-transfected with POU1F1-Wt $(p<0.05)$. POU1F1- $\gamma$ induced a $38 \%$ reduction (from 36.4 to 22.4 fold) while POU1F1- $\delta$ induced a $60 \%$ reduction (from 36.4 to 14.6 fold) on the $\mathrm{Wt}$ transcriptional activity. These results suggest that both variants (POU1F1- $\gamma$ and POU1F1- $\delta$ ) act as dominant negative repressors of the POU1F1Wt transcription factor on the PRL promoter activation.

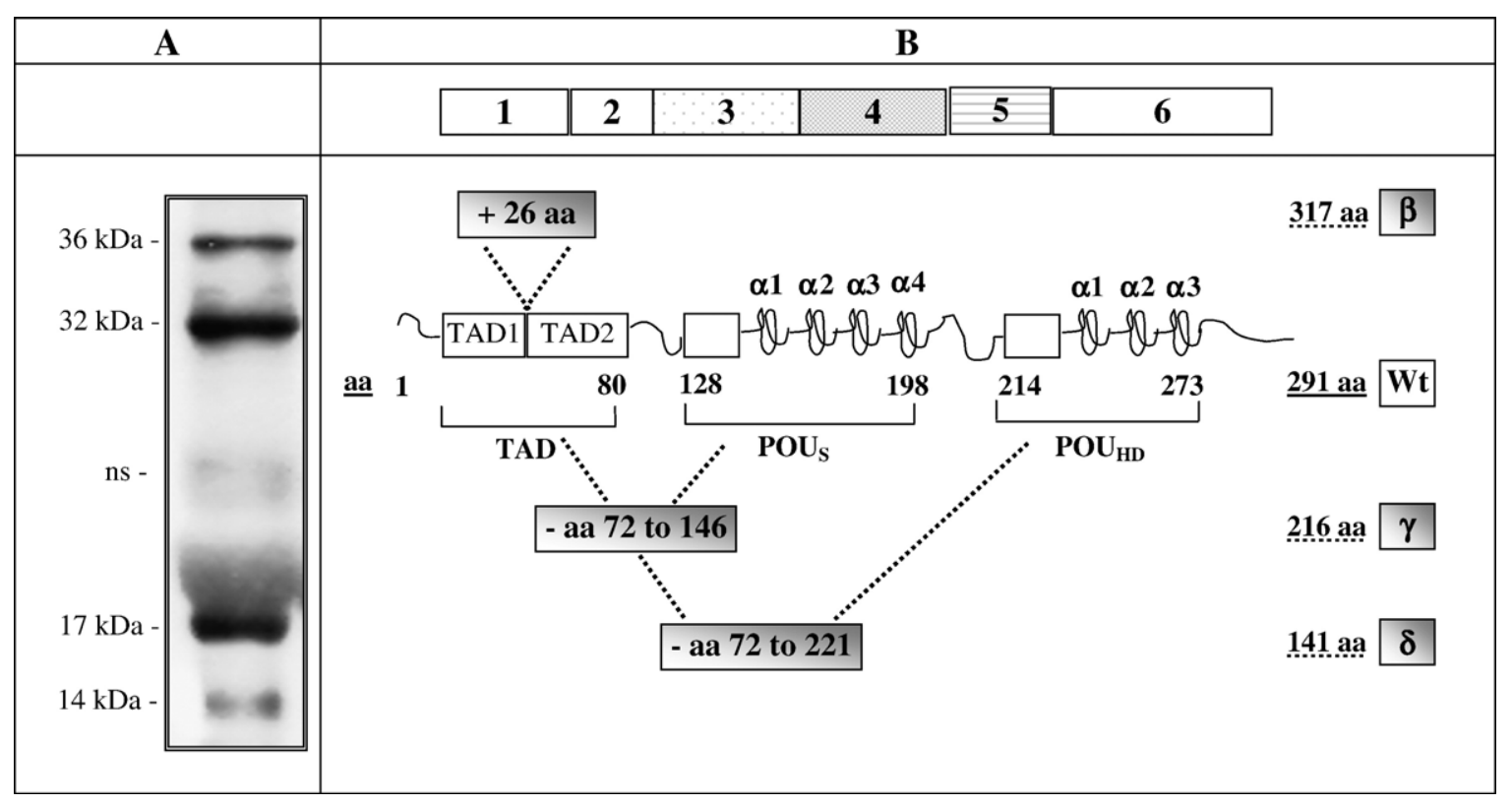

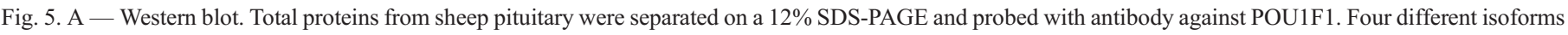

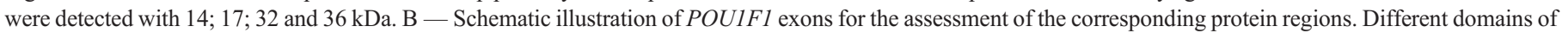

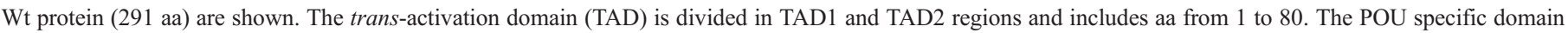

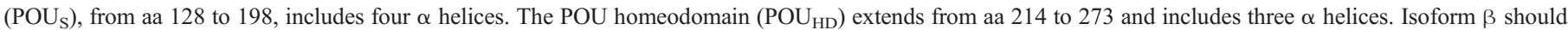

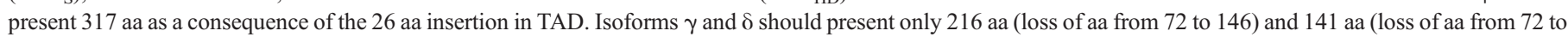
221), respectively. 
In order to confirm the negative repressor activity of these splicing variants, increasing amounts of the $P O U 1 F 1-\gamma$ expression vector were transfected (Fig. 3-A). Beginning with $0.15 \mu \mathrm{g}$ of $P R L$-Luc reporter vector and $0.3 \mu \mathrm{g}$ of $\mathrm{pRSV}-\mathrm{Wt}$ expression vector, the result obtained was 23 -fold activation. This value decreased $26 \%, 39 \%$ and $65 \%$ when $0.3 \mu \mathrm{g}, 0.6 \mu \mathrm{g}$ and $1.2 \mu \mathrm{g}$ of $\mathrm{pRSV}-\gamma$ were added, respectively. The same type of experiment was performed with $P O U 1 F 1-\delta$, starting again with $0.15 \mu \mathrm{g}$ of $P R L$-Luc and $0.3 \mu \mathrm{g}$ of $\mathrm{pRSV}-\mathrm{Wt}$. The resulting activation of $P R L$ promoter suffered a decline of $24 \%, 44 \%$ and $69 \%$, with addition of $0.3 \mu \mathrm{g}, 0.6 \mu \mathrm{g}$ and $1.2 \mu \mathrm{g}$ of POU1F1- $\delta$, respectively (Fig. 3-B).

\subsection{Trans-activation of the growth hormone promoter}

The transcriptional activity of all four POU1F1 splicing variants on the $G H$ promoter was also analysed by cell line transfection assays, using RAT-6 fibroblast cell line, which showed the lowest basal levels of $G H$ promoter activity. Fig. 4 shows the result of the trans-activation of luciferase reporter construct, under the $G H$ promoter control, by the different POU1F1 ORFs expression vectors.

POU1F1-Wt and POU1F1- $\beta$ showed a strong (12 and 13 fold, respectively) trans-activation activity on the $G H$ promoter. POU1F1- $\gamma$ and POU1F1- $\delta$ did not display transcriptional activation of the $G H$ promoter. When $\mathrm{Wt}$ and $\beta$ POUIF1 expression vectors were added simultaneously, the $G H$ promoter activity increased to 26 fold suggesting the existence of a strong cooperation between both POU1F1 isoforms. In contrast, POU1F1- $\gamma$ and POU1F1- $\delta$ variants inhibited significantly $(p<0.001)$ the POU1F1-Wt transcriptional activation $(52 \%$ and $75 \%$, respectively), acting as dominant negative repressors.

\subsection{POU1F1 protein isoforms detected in the ovine pituitary tissue}

In order to detect the protein isoforms included in the ovine pituitary, a Western blot assay was performed using an antibody against POU1F1-Wt (Fig. 5-A). Four different protein bands were detected with an apparent molecular weight of 36, 32, 17 and $14 \mathrm{kDa}$. A no-primary antibody control was tested, presenting no detection signal (data not showed).

Fig. 5-B shows a schematic illustration of the four POU1F1 ORFs studied in the present work. The POU1F1-Wt protein (291 aa) have the trans-activation domain (TAD) and $\mathrm{POU}_{\mathrm{S}}$ and $\mathrm{POU}_{\mathrm{HD}}$ DNA-binding domains. The other three POU1F1 proteins are characterized in terms of the structural modifications relatively to POU1F1-Wt. The insertion of 26 aa into the TAD results in POU1F1- $\beta$ isoform that consequently present 317 aa. POU1F1- $\gamma$ presents 216 aa as a consequence of the loss of 75 aa from positions 72 to 146 of the Wt. The POU1F1- $\delta$ isoform presents only 141 aa because 150 aa, between positions 72 and 221 of the POU1F1-Wt, are deleted (Fig. 5-B).

\section{Discussion}

Alternative pre-mRNA splicing is a very common process that was initially considered an exception and nowadays is rather the rule. It is now accepted that more than $74 \%$ of the human genes have splicing variants (Johnson et al., 2003; Kampa et al., 2004). As with other transcription factor genes, differential splicing of the POU1F1 gene gives rise to mRNAs and protein variants with potential different biological activities.

In this paper we show: first, the existence of four splicing mRNAs of POU1F1 gene in the pituitary of $O$. aries. The size of the ORFs is $876 \mathrm{nt}(\mathrm{Wt})$ and $954 \mathrm{nt}(\beta)$ as a consequence of a $78 \mathrm{nt}$ in-frame insertion. $\gamma$ ORF has $651 \mathrm{nt}$ as a consequence of the loss of $225 \mathrm{nt}$ from exon 3 and $\delta$ ORF has only $426 \mathrm{nt}$ due to the loss of $450 \mathrm{nt}$ from exons 3, 4 and 5 simultaneously.

Second, the existence of four different protein in the ovine pituitary corresponding, approximately to the expected MWs for the four isoforms: Wt and $\beta$ variants with 32 and $36 \mathrm{kDa}$, and two smaller proteins $\gamma$ and $\delta$ with 24 and $16 \mathrm{kDa}$. The two last values are above the observed MWs in the Western blot (17 kDa for the $\gamma$ isoform and $14 \mathrm{kDa}$ for the $\delta$ isoform). The possible explanations for this observation are a disturbed mobility of the lower bands in the SDS-PAGE and a post-translational modification of POU1F1 proteins.

Third, the protein level of the $\beta$ isoform is eight times lower than $\mathrm{Wt}$ in the ovine pituitary, confirming the results obtained in rat pituitary tumour GH3 cells (Morris et al., 1992; Konzak and Moore, 1992). Nevertheless, the amount of $\beta$ protein is high for a transcription factor, once POU1F1 total protein represents approximately $0.5 \%$ of the total nuclear proteins of different pituitary cell lines (Fox et al., 1990). The fact that the $\beta$ POU1F1 variant has been found in different mammals with a high level of conservation and that a very similar insertion of 28 aa is constitutively present in the same position in the POU1F1 of birds and fishes (Chiu et al., 2002), raises the possibility of an important functional role of this variant. This hypothesis was analysed in the present work regarding the $P R L$ and $G H$ promoter transcriptional activation achieved by both $\mathrm{Wt}$ and $\beta$ variants.

Four, the ovine POU1F1- $\beta$ isoform has a reduced capacity to trans-activate the $P R L$ promoter $(12 \%$ of the $\mathrm{Wt})$ but it shows a strong trans-activation of the $G H$ promoter, similar to Wt. In addition, we observed that the $\beta$ variant can cooperate strongly (significance $p<0.001$ ) with POU1F1-Wt on the transactivation of $G H$ promoter. $\beta$ variant showed no significant effect on the PRL promoter, comparing with $\mathrm{Wt}$ alone. The function of POU1F1- $\beta$ variant has been analysed by other authors. Morris et al. (1992), Konzak and Moore (1992) and Theill et al. (1992) agreed that, similarly to our results, the rat $\beta$ variant has only 5 to $10 \%$ of the Wt capacity to trans-activate the $P R L$ promoter. In agreement with our results, Haugen et al. (1994) observed that, in HeLa cells, the $\beta$ variant stimulated $G H$ promoter but had almost no effect on $P R L$ promoter. When both isoforms are co-expressed, contradictory results were described: Theill et al. (1992) and Vila et al. (1993) observed a dominant negative repressor effect of the $\beta$ variant, while Konzak and Moore (1992) observed that Wt and $\beta$ are not antagonists, they can function together and interact in the activation of the rat $P R L$ promoter when co-expressed, in agreement with the results of the present work. Diamond and Gutierrez-Hartmann (2000) stated that, in pituitary cell lines, POU1F1- $\beta$ represses $P R L$ 
promoter, but in non-pituitary cells, like HeLa cells, the rat $\beta$ variant presented a higher capacity to activate $P R L$ promoter. They performed an epitope-scanning and an alanine-scanning mutagenesis of the $\beta$ domain and showed that some aa residues were essential for this behaviour. Three out of five aa residues pointed out, by the authors, as the most important, are changed in the $O$. aries $\beta$ domain, presented in this work. These findings confirm that the precise sequence of this domain is decisive for the properties of repression or enhancement of the POU1F1 isoform.

Fifth, the two smaller variants of POU1F1 ( $\gamma$ and $\delta)$ are not capable to trans-activate the $P R L$ or $G H$ promoters. Both proteins are dominant negative repressors of POU1F1-Wt, reducing significantly the trans-activation of both $P R L$ and $G H$ promoters. A variant similar to $\gamma$ was previously described in pig pituitaries as $\delta 3$ (Yu et al., 2001). This variant did not show DNA-binding activity on rat $G H$ or $P R L$ promoters and did not interfere with Wt-POU1F1 function on a band shift in vitro assay. Our results, obtained by using a transcriptional functional assay, suggest a protein competition between $\mathrm{Wt}$ and $\gamma($ or $\delta)$ POU1F1 and a mediator transcription factor or a nuclear protein involved in a structural organization of the chromatin. There are some examples of transcriptional activators and repressors that are encoded by the same gene, namely, the IPOU and its alternative splice form (twin of I-POU), in Drosophila melanogaster, that act as inhibitor and activator of gene transcription (Treacy et al., 1992). Regarding the POU1F1 gene, Voss et al. (1993) described an alternative spliced form (Pit-1 $\Delta 4$ ) in rat, lacking exon 4, and confirmed that it was not competent in the activation of prolactin promotor. Day and Day (1994) showed that this transcript was a potential mediator of repression of prolactin gene expression in rat. In the present work, the $\delta$ variant lacks equally exon 4 , besides exons 5 and 6 and shows the same behaviour.

An important question still remain to be answered: why are there so many alternative splicing forms of the POU1F1 gene? The explanation should be connected to the many different functions of $P O U 1 F 1$ gene in the pituitary tissue: 1) the fineregulation of $G H$ and $P R L$ promoters. Extracellular signals (from the hypothalamus or the neurohypofisis) may regulate the expression of specific POU1F1 isoforms, increasing or decreasing the level of transcription of $G H$ and $P R L$ genes and promoting changes on the level of GH and PRL hormones; 2) the self-regulation of the POU1F1 gene expression during the organogenesis of the pituitary in early development stages; 3 ) the cell-type specific gene expression in thyrotrophs, somatotrophs and lactotrophs cells of the adult pituitary; 4) regulation on different physiological states of the animal. The age and sex of animals may also have an impact on the pattern of the POU1F1 gene-splicing variants; and 5) the POU1F1 isoforms can also regulate, indirectly, the expression of many different genes in the pituitary. Diamond and Gutierrez-Hartmann (2000) showed that POU1F1- $\beta$ altered the histone acetylation state of the proximal prolactin promoter and Kievit and Maurer (2005) believe that POU1F1 likely can modulate the chromatin structure. It is reasonable to postulate that different splicing forms of $P O U 1 F 1$ gene can specifically modulate the chromatin structure, facilitating the recruitment and subsequent transcriptional activation by other transcription factors in pituitary cells.

It is increasingly clear that the GH secretion of anterior pituitary is under control of multiple hypothalamic releasing hormones, paracrine factors and peripheral hormones/factors acting directly on the somatotroph cells. It may be questioned whether different subtypes of somatotrophs exist and are stimulated by different secretagogues. Multiple hypothalamic peptides stimulate GH release from the somatotroph acting via GH releasing hormone-receptors, $\mathrm{GH}$ secretagogue (GHS) receptor and pituitary adenylate cyclase activating peptide (PACAP) receptor. It is possible that different isoforms of POU1F1 transcription factor will regulate the transcriptional expression of specific secretagogues-receptor genes. In addition, this might support the existence of different sub-types of somatotrophs responding to different hypothalamic secretagogues with specific POU1F1 isoforms in the cells.

Further studies in ruminant and other animal models will contribute to a better understanding of the molecular mechanisms controlling the hormonal secretion in the anterior pituitary.

\section{Acknowledgments}

The luciferase GH and PRL reporter vectors were kindly provided by Dr. Michael Karin (University of California, San Diego, UCSD) and Dr. Gutierrez-Hartmann (University of Colorado Health Sciences Center).

The authors wish to thank ANCOTEQ (Associação Nacional de Criadores de Ovinos Churra da Terra Quente) and DRATM (Direcção Regional de Agricultura de Trás-os-Montes) for kindly providing the animals; Prof. J. Azevedo and Eng. P. Fontes (Department of Zootechnic, UTAD) for facilitating the slaughter of the animals according to legislation and ethical procedures; and Prof. I. Dias (Department of Veterinary Science, UTAD) for the pituitary extraction. E.B. thanks FCT (Fundação para a Ciência e a Tecnologia) and ESF (EC-III 390 Framework Programme) for the Ph.D. grant (BD-1365/2000). R. Renaville thanks FNRS (Fonds National de la Recherche Scientifique) for the funds (\#2.4524.01). CBMSO has been benefited from an institutional grant from Fundación Ramón Areces (Spain).

\section{References}

Bastos, E., et al., 2006. Ovis aries POU1F1 gene: cloning, characterization and polymorphism analysis. Genetica 126 (3), 303-314.

Berget, S.M., Moore, C., Sharp, P.A., 1977. Spliced segments at the $5^{\prime}$ terminus of adenovirus 2 late mRNA. Proc. Natl. Acad. Sci. U. S. A. 74 (8), 3171-3175.

Bodner, M., Castrillo, J.L., Theill, L.E., Deerinck, T., Ellisman, M., Karin, M., 1988. The pituitary-specific transcription factor GHF-1 is a homeoboxcontaining protein. Cell 55, 505-518.

Brett, D., Pospisil, H., Valcárcel, J., Reich, J., Bork, P., 2002. Alternative splicing and genome complexity. Nat. Genet. 30, 29-30.

Chen, R., Ingraham, H., Treacy, M.N., Albert, V.R., Wilson, L., Rosenfeld, M.G., 1990. Autoregulation of PIT-1 gene expression mediated by two cis-active promoter elements. Nature 346, 583-586.

Chiu, C.C., Ting, J.W., Hseu, T.H., Chang, C.Y., 2002. Characterization of transactivation domain and developmental expression of pituitary specific transcription factor, Pit-1 of ayu (Plecoglossus altivelis). Gen. Comp. Endocrinol. 127, 307-313. 
Chomczynski, P., Sacchi, N., 1987. Single-step method of RNA isolation by acid guanidinium thiocyanate-phenol-chloroform extraction. Anal. Biochem. 162, 156-159.

Day, R.N., Day, K.H., 1994. An alternatively spliced form of Pit-1 represses prolactin gene expression. Mol. Endocrinol. 8 (3), 374-381.

Delhase, M., Vila, V., Hooghe-Peters, E.L., Castrillo, J.L., 1995. A novel pituitary transcription factor is produced by alternative splicing of the human GHF-1/PIT-1 gene. Gene 155, 273-275.

Diamond, S.E., Gutierrez-Hartmann, A., 2000. The Pit-1 $\beta$ domain dictates active repression and alteration of histone acetylation of the proximal prolactin promoter. J. Biol. Chem. 275 (40), 30977-30986.

Fox, S.R., Jong, M.T.C., Casanova, J., Ye, Z.S., Stanley, F., Samuels, H.H., 1990. The homeodomain protein, Pit-1/GHF-1, is capable of binding to and activating cell-specific elements of both the growth hormone and prolactin gene promoters. Mol. Endocrinol. 4, 1069-1080.

Haugen, B.R., Gordon, D.F., Nelson, A.R., Wood, W.M., Ridgway, E.C., 1994 The combination of Pit-1 and Pit-1T have a synergistic stimulatory effect on the thyrotropin $\beta$-subunit promoter but not the growth hormone or prolactin promoters. Mol. Endocrinol. 8, 1574-1582.

Ingraham, H., et al., 1988. A tissue-specific transcription factor containing a homeodomain specifies a pituitary phenotype. Cell 55, 519-529.

Johnson, J.M., et al., 2003. Genome-wide survey of human alternative premRNA splicing with exon junction microarrays. Science 302, 2141-2144.

Kampa, D., et al., 2004. Novel RNAs identified from an in-depth analysis of the transcriptome of human chromosomes 21 and 22. Genome Res. 14, $331-342$.

Kievit, P., Maurer, R.A., 2005. The pituitary-specific transcription factor, Pit-1, can direct changes in the chromatin structure of the prolactin promoter. Mol. Endocrinol. 19 (1), 138-147.

Konzak, K.E., Moore, D.D., 1992. Functional isoforms of Pit-1 generated by alternative messenger RNA splicing. Mol. Endocrinol. 6 (2), 241-247.

Lefevre, C., Imagawa, M., Dana, S., Grindlay, J., Bodner, M., Karin, M., 1987. Tissue-specific expression of the human growth hormone gene is covered in part by the binding of a specific trans-acting factor. EMBO J. 6, 971-981.

Li, S., Crenshaw III, E.B., Rawson, E.J., Simmons, D.M., Swanson, L.W., Rosenfeld, M.G., 1990. Dwarf locus mutants lacking three pituitary cell types result from mutations in the POU-domain gene PIT-1. Nature 347, 528-533.

Malagon, M.M., et al., 1996. J. Histochem. Cytochem. 44, 621-627.

McCormick, A., Brady, H., Theill, L.E., Karin, M., 1990. Regulation of the pituitary-specific homeobox gene POU1F1 by cell-autonomous and environmental cues. Nature 345, 829-832.
Modrek, B., Lee, C., 2002. A genomic view of alternative splicing. Nat. Genet. 30, 13-19.

Morris, A.E., Kloss, B., McChesney, R.E., Bancroft, C., Chasin, L.A., 1992. An alternatively spliced Pit-1 isoform altered in its ability to trans-activate. Nucleic Acids Res. 20 (6), 1355-1361.

Nelson, C., Albert, V.R., Elsholtz, H.P., Lu, L.I.W., Rosenfeld, M.G., 1988. Activation of cell-specific expression of rat growth hormone and prolactin genes by a common transcription factor. Science 239, 1400-1405.

Schanke, J.T., Conwell, C.M., Durning, M., Fisher, J.M., Golos, T.G., 1997. Pit1/Growth Hormone Factor 1 splice variant expression in the rhesus monkey pituitary gland and the rhesus and human placenta. J. Clin. Endocrinol. Metab. 82 (3), 800-807.

Sharp, P.A., 1994. Split genes and RNA splicing. Cell 7, 805-815.

Simmons, D.M., et al., 1990. Pituitary cell phenotypes involve cell-specific Pit-1 mRNA translation and synergistic interactions with other classes of transcription factors. Genes Dev. 4, 695-711.

Theill, L.E., Castrillo, J.L., Wu, D., Karin, M., 1989. Dissection of functional domains of the pituitary-specific transcription factor GHF-1. Nature 342, 945-948.

Theill, L.E., Hattori, K., Lazzaro, D., Castrillo, J.L., Karin, M., 1992. Differential splicing of the GHF1 primary transcript gives rise to two functionally distinct homeodomain proteins. EMBO J. 11, 2261-2269.

Thomas, M.G., Carroll, J.A., Raymond, S.R., Matteri, R.L., Keisler, D.H., 2000. Transcriptional regulation of pituitary synthesis and secretion of growth hormone in growing wethers and the influence of zeranol on these mechanisms. Domest. Anim. Endocrinol. 18, 309-324.

Treacy, M.N., Neilson, L.I., Turner, E.E., He, X., Rosenfeld, M.G., 1992. Twin of I-POU: a two amino acid difference in the I-POU homeodomain distinguishes an activator from an inhibitor of transcription. Cell 68, 491-505

Vila, V., Jimenez, O., Guell, A., Castrillo, J.L., 1993. Pit-1 and Pit-2 role in growth hormone gene regulation. J. Pediatr. Endocrinol. 6 (3-4), 225-228.

Voss, J.W., Wilson, L., Rhodest, S.J., Rosenfeld, M.G., 1993. An alternative Pit1 RNA splicing product reveals modular binding and nonmodular transcriptional activities of the POU-specific domain. Mol. Endocrinol. 7, $1551-1560$.

Yu, T.P., Sun, H.S., Wahls, S., Sanchez-Serrano, I., Rothschild, M.F., Tuggle, C.K., 2001. Cloning of the full length pig PIT1 cDNA and a novel alternative PIT1 transcript, and functional studies of their encoded proteins. Anim. Biotechnol. $12(1), 1-19$. 